\title{
Impact of climate change on livestock productivity: A review
}

Madziga, I. I.

National Animal Production Research Institute,

Ahmadu Bello University, Shika-Zaria

Abstract

Corresponding author: iimadziga2k@gmail.com; +24 7037063934

Climate change is a long-term shift in the statistics of the weather such as temperature, radiation, and wind and rainfall characteristics of a particular region. Sustainability in livestock production system is largely affected by climate change. A disproportion between metabolic high temperature production inside the animal body and its dissipation to the surroundings results to heat stress under high air temperature and humid climates. The foremost reaction of animals under thermal weather is an increase in respiration rate, rectal temperature and heart rate. The anticipated rise in temperature due to climate change is likely to aggravate the heat stress in livestock, adversely affecting their productive and reproductive performance and even death in extreme cases. The predicted negative impact of climate change on agriculture would also adversely affect livestock production by aggravating the feed and fodder shortages. The paper mainly reviews the impacts of climate change on livestock productive performance.

Keywords: Livestock, productivity, temperature, climate, heat stress

\section{Impact du changement climatique sur la productivité du bétail: un bilan}

\section{Résumé}

Le changement climatique est un changement à long terme dans les statistiques météorologiques telles que la température, le rayonnement et les caractéristiques $d u$ vent et des précipitations d'une région particulière. La durabilité du système de production de bétail est largement affectée par le changement climatique. Une disproportion entre la production métabolique à haute température à l'intérieur du corps de l'animal et sa dissipation dans l'environnement entraîne un stress thermique sous des températures élevées de l'air et des climats humides. La réaction la plus importante des animaux sous temps thermique est une augmentation de la fréquence respiratoire, de la température rectale et de la fréquence cardiaque. L'augmentation prévue de la température due au changement climatique est susceptible d'aggraver le stress thermique du bétail, affectant négativement ses performances productives et reproductives et même la mort dans les cas extrêmes. L'impact négatif prévu du changement climatique sur l'agriculture aurait également un effet négatif sur la production animale en aggravant les pénuries d'aliments et de fourrage. Le document passe principalement en revue les impacts du changement climatique sur les performances de production de bétail.

Mots clés: Bétail, productivité, température, climat, stress thermique

\section{Introduction}

Livestock play a major role in the agricultural sector in developing nations, and the livestock sector contributes $40 \%$ to the agricultural GDP. Global demand for foods of animal origin is growing and it is apparent that the livestock sector will need to expand (FAO, 2009). Livestock are adversely affected by the detrimental effects of extreme weather. Climatic 


\section{Impact of climate change on livestock productivity: A review}

extremes and seasonal fluctuations in herbage quantity and quality will affect the well-being of livestock, and will lead to declines in production and reproduction efficiency (Sejian, 2013). Climate change is a major threat to the sustainability of livestock systems globally. Therefore, adaptation to, and alleviation of the injurious effects of thrilling climates has played a key part in fighting the climatic influence on livestock (Sejian et al., 2015). There is little doubt that climate change will have an impact on livestock performance in many regions and as per most predictive models the impact will be detrimental. Climate change manifests itself as swift changes in climate within a couple of years over decades. In general, climate change is linked with an increasing global temperature. Various climate model projections suggest that by the year 2100 , mean global temperature may be $1.1-6.4{ }^{\circ} \mathrm{C}$ warmer than in 2010. The difficulty facing livestock is changes in weather conditions, e.g. intense heat waves, floods and droughts. In addition to production losses, extreme events also result in livestock death (Gaughan and Cawsell-Smith, 2015). Animals can adapt to hot climates, however, the response mechanisms that are helpful for survival may be harmful to performance. This article is aimed at reviewing the adverse impact of climate change on livestock production.

\section{Direct effects of climate change on livestock}

The most significant direct impact of climate change on livestock production comes from the heat stress. Heat stress results in a significant financial burden to livestock producers through decrease in milk component and milk production, meat production, reproductive efficiency and animal health. Thus, an increase in air temperature, such as that predicted by various climate change models, could directly affect animal performance. Fig.1 describes the various impacts of climate change on livestock production.

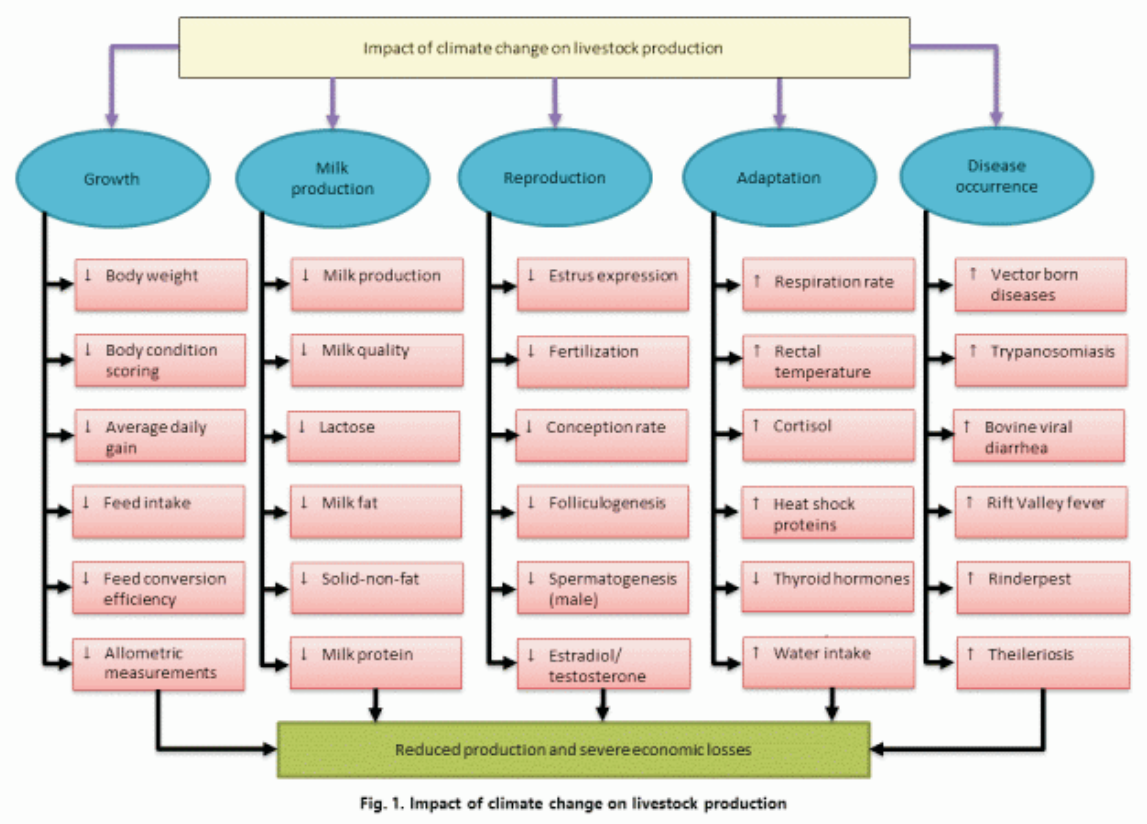

Adopted from Sejian et al. (2016) 


\section{Madziga}

Indirect effects of climate change on livestock

Most of the production losses are incurred via indirect impacts of climate change largely through reductions or nonavailability of feed and water resources. Climate change has the potential to impact the quantity and reliability of forage production, quality of forage, water demand for cultivation of forage crops, as well as large-scale rangeland vegetation patterns. In the coming decades, crops and forage plants will continue to be subjected to warmer temperatures, elevated carbon dioxide, as well as wildly fluctuating water availability due to changing precipitation patterns. Climate change can adversely affect productivity, species composition, and quality, with potential impacts not only on forage production but also on other ecological roles of grasslands (Giridhar and Samireddypalle, 2015). Due to the wide fluctuations in distribution of rainfall in growing season in several regions of the world, the forage production will be greatly impacted. With the likely emerging scenarios that are already evident from impact of the climate change effects, the livestock production systems are likely to face more of negative than the positive impact. Also climate change influences the water demand, availability and quality. Changes in temperature and weather may affect the quality, quantity and distribution of rainfall, snowmelt, river flow and groundwater. Climate change can result in a higher intensity precipitation that leads to greater peak run-offs and less groundwater recharge. Longer dry periods may reduce groundwater recharge, reduce river flow and ultimately affect water availability, agriculture and drinking water supply. The deprivation of water affects animal physiological homeostasis leading to loss of body weight, low reproductive rates and a decreased resistance to diseases (Naqvi et al., 2015). More research is needed into water resources' vulnerability to climate change in order to support the development of adaptive strategies for agriculture. In addition, emerging diseases including vector borne diseases that may arise as a result of climate change will result in severe economic losses.

\section{Effect of heat stress on the production of farm animals and product quality}

\section{Meat and egg production in poultry}

There is a large number of reports on the effects of high ambient temperature and humidity on poultry production, since the poultry industry is concentrated in hot climate areas of the world, mainly in Asia and South America (Daghir, 2009). However, their higher production performance and feed conversion efficiency make today's chickens more susceptible to heat stress than ever before (Lin et al., 2006). The thermoregulation characteristics of poultry differ to some extent from those of mammals due to their high rate of metabolism associated with more intensive heat production and low heat dissipation capacity caused by their feathers and lack of sweat glands. Evaporative cooling is achieved exclusively by panting. In the first days of their life poults need hot climate $\left(32-38{ }^{\circ} \mathrm{C} \quad\right.$, , but the optimal temperature decreases rapidly with age by 2.5-3.0 ${ }^{\circ} \mathrm{C}$ per week (FASS, 2010). After feathering birds prefer mean ambient temperatures between $18-22{ }^{\circ} \mathrm{C}$ for their growth performance and egg production although the optimal temperature for feed efficiency is higher. The crucial temperature for poultry is $30^{\circ} \mathrm{C}$, because up to this point birds, through a better feed conversion rate and lower basal metabolic rate, are able to compensate for the energy loss caused by the lower feed intake (Daghir, 2009). Above $30{ }^{\circ} \mathrm{C}$ the feed and energy intake declines to such an extent that birds are not able to 


\section{Impact of climate change on livestock productivity: A review}

compensate for it, production declines rapidly and the rate of mortality increases.

The reduction of feed consumption in response to high temperatures is closely associated with the severity and duration of exposure. In broilers the rate of feed refusal during heat stress increases with age (Gonzalez-Esquerra and Leeson, 2005) and can be as high as $50 \%$.

Accordingly, layers reduce their feed intake by approximately $30-50 \%$ in severe heat stress $\left(34-35^{\circ} \mathrm{C}\right)$. In addition, several studies reported that high ambient temperatures decrease the digestibility of nutrients in poultry likely due to a reduced activity of trypsin, chymotrypsin, and amylase (Hai et al., 2000). Consequently, the lower and by most probability insufficient nutrient supply limits egg production and egg mass in layers, and the growth rate in broilers. During heat stress birds lose a large amount of carbon dioxide by panting; $\mathrm{CO}_{2}$ however, is essential for Ca-carbonate in eggshell formation. Therefore, in addition to an insufficient nutrient supply, the compromised egg shell formation limits the egg production further (egg/day or egg production/number of birds), which can be very substantial as the egg production percentage might decline from $80-90 \%$ to $50-60 \%$, with a $10 \mathrm{~g}$ lower egg weight on average (Mashaly et al., 2004). Furthermore, the lack of carbon dioxide results in decreasing eggshell thickness and an increasing number of broken eggs that further aggravates the profit losses in hens kept in a hot environment. As mentioned before, hyperventilation during heat stress results in respiratory alkalosis due to the high rate of $\mathrm{CO}_{2}$ excretion. This means that there will be an excess of alkaline metabolites in the body, as the formation of $\mathrm{HCO}_{3}{ }^{-}$is insufficient due to the high loss of $\mathrm{CO}_{2}$. In order for the body to be able to maintain the homeostasis of electrolytes in body fluids it increases the level of $\mathrm{K}^{+}$and
$\mathrm{Na}^{+}$excreted in the faeces and urine, while the $\mathrm{Cl}^{-}$concentration of the blood rises. Due to the anyway considerable surplus of $\mathrm{Cl}$ ion it is recommended to discontinue chlorination - where chlorinated water is used - on extremely hot days (Daghir, 2009). The high rate of monovalent ion discharge also impairs the water balance of the birds. Despite the fact that at high temperatures the birds have a higher water intake, the water retention capacity of the body decreases significantly due to the altered electrolyte balance; accordingly, the reduction in intracellular water alters the osmotic pressure and electrical potential of cell membranes as well as the intracellularextracellular. Effect of heat stress on different production parameters in commercial laying hens kept different thermal conditions (Mashaly et al., 2004), homeostasis (Borges et al., 2003). The lack of homeostasis and the heat stress per se accelerate the production of free radicals in the body and lead to a higher risk for oxidation, which is detrimental for the hatchability of eggs, as well as for the growth performance and meat quality of poultry. Broilers were observed to respond to high ambient temperatures by a decreased protein synthesis and increased protein breakdown (reviewed by Lin et al., 2006). This appears to be supported by trial findings that report lower body protein and muscle tissue protein plus higher fat levels in heat stress (Gonzalez-Esquerra and Leeson, 2005; Aksit et al., 2006). The deterioration of meat quality is not limited to the altered protein/fat ratio, as the mobilization of minerals and vitamins from tissues due to heat stress (Sahin et al., 2009) further compromises the nutritive value of eggs and meat (Sahin et al., 2002). The prevalence of other deficiencies of meat quality, such as high drip loss, too pale color (Aksit et al, 2006), and PSE (pale, soft and exudative) meat also increase (McKee and Sams, 1997) and these contribute to a 


\section{Madziga}

significant decline in consumer confidence. In summary, high ambient temperatures impair egg production by decreasing the number and weight of eggs as well as by reducing the eggshell quality, whereas in meat-type chickens, lower growth rates and higher feed per gain ratios are predominant. The deterioration of meat quality traits due to heat stress occurs mainly in consequence of the associated higher rate of lipid peroxidation and the altered electrolyte balance.

\section{Pig performance and pork quality}

The climate change with rising mean temperatures may cause a permanent stress load for pigs, especially in continental summer or warmer climate areas. The upper critical temperature for pigs from nursery to adult ages is $25-26^{\circ} \mathrm{C}$; however, some research data suggest that the optimal temperature decreases with the increase in body weight. The heavier an animal, the less ability it has to lose heat due to the relative small surface area compared to its body weight. In consequence feed refusal increases with body weight at high ambient temperatures (Close, 1989; Quiniou et al., 2000). In case of sows kept at high ambient temperatures $\left(29^{\circ} \mathrm{C}\right.$ vs $\left.18^{\circ} \mathrm{C}\right)$ the feed intake over the entire lactation period may fall back by more than $50 \%$, resulting in a loss of body condition far exceeding the optimum and also leads to poorer growth of the piglets. The condition of the sows is also in close correlation with the number of days to oestrus and the reproductive performance. Studies with pair fed sows showed that the energy metabolism and hormonal status of the animals changed during heat stress and the lower milk production is not exclusively explained by the reduced feed intake (Messias de Bragan et al., 1998). Renaudeau et al. (2003) suggests, that the apparent inefficiency of the sow mammary gland in hot conditions could be attributed to an increased rate of blood flow irrigating the skin capillaries in order to dissipate body heat and this in turn results in a lower blood flow to the mammary gland cells. Feeding high fat diets (125 $\mathrm{g}$ fat per $\mathrm{kg}$ of dry matter) to the sows during lactation in order to alleviate hyperthermia leads to decreased heat production, which may reduce the feed refusal of the sows kept at high ambient temperatures (Babinszky, 1998). Feeding high fat diets also improves the energetic efficiency of milk production when compared to sows fed high starch diets (with low dietary fat levels). From the aspect of energetic efficiency milk fat production is more efficient from dietary fat than from dietary carbohydrates because it is converted more directly (Babinszky, 1998). Since the milk production of the lactating sow determines the performance of the suckling pigs in terms of their growth rate, mortality and morbidity, any reduction in the milk yield will have a negative impact on the profitability of pig production. Moreover, heat may also compromise the parameters of fertility: the quality of eggs and sperm deteriorates; embryo mortality between days 1 to 15 increases and maturity is delayed. In consequence, the number of piglets per sow may be less when sows are exposed to high ambient temperatures for longer periods of time. High temperatures cause loss of appetite in pigs; however, both the upper critical temperature and the rate of feed refusal are influenced by the relative humidity of the air (Collin et al., 2001; Huynh et al., 2005). With the increase of humidity a $60-70 \mathrm{~kg}$ pig may lower its feed intake by up to $80-150 \mathrm{~g} /$ day (Huynh et al., 2005). The lower feed intake compromises the daily gain, however, after exposure to hot periods of $30-33^{\circ} \mathrm{C}$ pigs display compensatory growth, they overcome their heat stress and grow further, but they can't compensate for temperatures as high as $36^{\circ} \mathrm{C}$ (Babinszky et al., 2011). There is a curvilinear relationship between the increase of temperature and the average 


\section{Impact of climate change on livestock productivity: A review}

daily gain and feed conversion rate of pigs fed ad libitum (reviewed by Noblet et al., 2001). The average daily gain reaches its maximum between temperatures of 15 to $25^{\circ} \mathrm{C}$ in young pigs (up to $30-34 \mathrm{~kg}$ ) and between $10-20^{\circ} \mathrm{C}$ in growing and finishing pigs. Both cold and severe heat stress compromise feed conversion; however, during moderate heat stress $\left(2-3^{\circ} \mathrm{C}\right.$ above the upper critical temperature) pigs have the ability to compensate for the lower feed intake by decreasing their maintenance related heat production. Besides constant heat stress, diurnal high temperatures can also be detrimental to pig performance. The average daily feed intake and the average daily gain decreased by 10 and $20 \%$, respectively, and the feed conversion (feed/gain) increased by approximately $8 \%$ when pigs were kept in a daily range of 22.5 to $35^{\circ} \mathrm{C}$ in contrast to the thermoneutral $\left(20^{\circ} \mathrm{C}\right)$ temperature (Lopez et al., 1991). In the interest of performance and immune response it is recommended to avoid any higher fluctuations $\left( \pm 12^{\circ} \mathrm{C}\right)$ of the mean of $20^{\circ} \mathrm{C}$ (Noblet et al., 2001). Recent publications highlight the fact that high temperatures not only impair growth but also change body composition and thus can impair the nutritive value and quality of pork. Prolonged heat stress $\left(30-33^{\circ} \mathrm{C}\right)$ reduces the rate of protein deposition in growing and finishing pigs (Kerr et al., 2003). As seen in the above, the lower protein deposition is probably not just in consequence of the lower nutrient supply. Halas et al. (2004) demonstrated in their model simulation that the rate of protein deposition is sensitive to any changes occurring in the maintenance energy requirement of the body. Heat stress triggers hormonal changes that influence the metabolism of nutrients. Reduced levels of thyroid hormones were consistently observed in swine kept in a hot environment in contrast to a thermoneutral milieu (Renaudeau et al., 2003). Thyroid hormones are responsible for the metabolic rate and thermogenesis besides influencing the protein turnover within the body. Although carcass fatness decreases as a result of lower feed intake during heat stress, the shift of fat distribution from external sites towards internal sites was found to be attributable to a reduced activity of the lipogenic enzyme in back fat and a higher activity of lipoprotein lipase in lean fat (Noblet et al., 2001). In conclusion, heat stress impairs feed intake and swine performance in the lactating sow and in growing and fattening pigs. The extent of this detrimental effect depends mainly on body weight and the actual temperature and relative humidity of the air. Recent studies show that growing and fattening pigs kept in hot environments deposit less protein, which compromises pork quality with regard to the protein to fat ratio in the meat. Any means of reducing heat production or increasing heat loss of the animals are beneficial in the efforts to avoid the weakening of the production potential of swine when facing with global warming.

Cattle production: milk production, milk quality and beef production

In dairy cows, similarly to other species the various factors of the environment, such as the average temperature, humidity and air velocity all play an important role in the fertility, reproductive performance and milk yield of the animals. This is particularly true in animals with high genetic potential. The optimal ambient temperature for dairy cows is between 5 to $15{ }^{\circ} \mathrm{C}$. Over $15{ }^{\circ} \mathrm{C}$ the animals start to sweat, although they are still able to maintain the equilibrium between heat production and heat dissipation. Heat dissipation by sweating gradually increases and although it becomes quite intense above the upper critical temperature $\left(25^{\circ} \mathrm{C}\right)$ the cow is no abler to maintain the heat balance at such high temperatures. Kadzere et al. (2002) found that on days of heat stress the amount of water lost through evaporation 


\section{Madziga}

may be up to or even exceed the amount of water excreted in the milk. The high rate of water loss stresses the importance of water supply for dairy cows at high temperatures. The efficiency of body cooling by evaporative water loss, however, decreases with the increase of humidity. The use of the Temperature-Humidity Index (THI) is suggested as an indicator of the thermal climatic conditions $(\mathrm{THI}=0.72(\mathrm{~W}+\mathrm{D})+$ 40.6 , where $\mathrm{W}$ is wet bulb and $\mathrm{D}$ is dry bulb temperature in $\left.{ }^{\circ} \mathrm{C}\right)$. When the THI is in the range of $72-80,80-90$ or $90-98$, the corresponding heat stress is mild, medium or severe. Both the increasing ambient temperature (from 25 to $32{ }^{\circ} \mathrm{C}$ ), and the increasing THI (from 73 to 82 ) have a negative impact on the dry matter intake and milk production of cows (Lopez et al., 1991). The relevant data show, that the shorter the animal is exposed to heat stress, the better they can tolerate it, although even a moderate heat stress will impair their production performance. As mentioned earlier, there are other environmental factors besides temperature and humidity that affect thermal sensation. According to the results of a model simulation the critical ambient temperature that can compromise the respiratory response of a $600 \mathrm{~kg}$ liveweight Holstein cow is largely dependent on the daily milk yield, coat depth, exposed surface area, air velocity and water vapor pressure (Berman, 2005) and in varying environmental conditions the upper critical temperature of the animals can fluctuate in a wide range $\left(8\right.$ to $\left.42{ }^{\circ} \mathrm{C}\right)$. The heat stress caused feed refusal predisposes the animal to certain metabolic disorders, first of all to ketosis. The occurrence of ketosis at herd level not only leads to a temporary decline in milk production, but in consequence of the mortalities may also cause a drop in the number of dairy cows. The adaptive mechanisms that serve survival, for instance in the case of harsh ambient temperatures, weaken the production performance. One element of the long-term adaptation to high temperatures is slowing the heart rate, which leads to a lower level of heat production associated with maintenance. At the same time circulation in the mammary glands is impaired, resulting in poorer milk yield. The ability of dairy cows to adapt to the changes of their environment depends on their genetic potential. The present-day selection for production weakens heat tolerance, thus combined selection for heat tolerance and production is recommended when facing the challenge of climate change (Ravagnolo and Misztal, 2000). The lower feed intake and higher water consumption during heat stress result in a modified fermentation and volatile fatty acid production in the rumen since the high temperature may affect the functioning of rumen bacteria. Of the volatile fatty acids produced in the rumen and transported to the bloodstream acetic acid is primarily used for lipid synthesis, while the level of propionic acid influences the protein content of milk. In a study with Jersey cows the proportion of acetic acid in the rumen contents as well as the ruminal $\mathrm{pH}$ significantly decreases when temperature of the environment where cows are kept rises to $30{ }^{\circ} \mathrm{C}$ instead of $20{ }^{\circ} \mathrm{C}$ (Bandaranayaka and Holmes, 1976). In consequence the protein and fat content of the milk, and also the proportion of middlechain fatty acids $\left(\mathrm{C}_{6}-\mathrm{C}_{14}\right)$ in milk fat decreased at high temperature. The lower feed intake caused by high ambient temperatures compromises the protein supply of the cows in an indirect manner as well, in so far as the lower rations mean less sulphur supply, which may limit the protein synthesis by rumen bacteria, and which certainly affects the level of the essential amino acid, methionine. The lower level of microbial protein, which has a crucial role in the protein supply of ruminants, and/or the lower methionine content in the rumen flora, clearly lead to a decrease of milk 


\section{Impact of climate change on livestock productivity: A review}

protein. Consequently, the sulphur supply of rumen flora should receive particular attention at high ambient temperatures in order to avoid the fall of milk protein. Several studies have confirmed that adequate sulphur supply yields further benefits. Adding potassium, sodium, or magnesium sulfate to diets of dairy cows may enhance the digestibility of dry matter; therefore, it is recommended to increase dietary sulfur during heat stress in order to improve the digestibility of nutrients and to maintain the protein content of milk (Kadzere et al., 2002). Heat stress increases loss of body fluids due to sweating and panting and results in an altered water balance of the body and the osmolarity of cells. Enhanced respiration associated with a higher rate of $\mathrm{CO}_{2}$ loss leads to an altered blood $\mathrm{pH}$ and respiratory alkalosis. An increased urinary $\mathrm{pH}$ can help to overcome alkalosis caused by the high excretion of bicarbonate $\left(\mathrm{HCO}_{3}{ }^{-}\right)$(Kadzere et al., 2002); however, these processes have energetic and thermoregulatory consequences. Excretion of sodium in the sweat and urine increases during heat stress, at the same time the level of $\mathrm{Na}$ available in the body determines, even if indirectly, the milk fat content. $\mathrm{NaHCO}_{3}$ acts as a key buffering agent in the rumen, alleviating the low-fat milk syndrome. Several studies have shown significant increases in the milk production of heat-stressed dairy cows when fed higher than recommended (NRC, 1989) concentrations of sodium $\left(\mathrm{NaHCO}_{3}\right)$ and potassium (i.e. $\mathrm{KCl}$ ) (reviewed by Silanikove et al. (1997).

In beef cattle the unfavorable meteorological conditions directly affect the animals and their physiology as discussed in the above section for dairy cows. Extreme weather conditions diminish the growth performance (weight gain, feed intake and feed conversion potential) of beef calves, particularly of those kept outdoors. Slower growth and smaller slaughter weight however are reflected in the quality of meat as well, since animals of the same age but smaller body weight have less muscle fat and also the taste panel traits of juiciness and tenderness are poorer (Keane and Allen, 1998). The predicted climate changes not only weaken the performance of livestock per se, but also compromise the conditions for production by reducing the quality of feedstuffs, as earlier discussed in this chapter. Increasing mean temperatures and declining precipitation reduce the dietary crude protein and digestible organic matter content of grass; it is unlikely, however, that any future increases in precipitation would compensate for the declines in forage quality following from the projected temperature increases (Craine et al., 2010). Aridity, water deficiency may lead to a drop in groundwater levels, alteration and thinning of pasture flora, and in consequence to a decline in feed supply, besides aggravating the problems of water supply (Babinszky et al., 2011). As a result, cattle are likely to experience greater nutritional stress in the future with the two options of either accepting the loss of performance or being prepared to provide supplemental nutrition to the extensive beef sector as well. Feeding concentrate to beef cattle increases the costs of beef production, and it may also affect the nutritive and health value of meat. In respect of fatty acid composition, numerous publications suggest that the meat of grass fed cattle contains more n-3 fatty acids and conjugated linoleic acid than meat from their concentrate fed peers (Scollan et al., 2006). These fatty acids play an important role in maintaining health and preventing diseases (i.e. cardio vascular diseases, cancer) and consumers are increasingly aware of these functional components of foods. In addition to the above-mentioned problems, extreme weather may result in respiratory disease, immune suppression 


\section{Madziga}

and thus higher mortality of the animals, which further reduces the profitability of beef production.

Summarizing the relevant data it can be stated that sever heat stress results in an average production loss of 1.5-2 liters/cow/day $(5-10 \%$ of the daily milk yield). Moreover, the altered rumen fermentation influences not only milk yield but also milk composition by reducing its protein and fat content. In case the predicted climate change occurs, the present beef production potential can only be maintained if supplemental feeds are offered, but this would significantly reduce the economic efficiency of cattle production and may have an impact on beef quality as well.

It is clear from the previous section that the efficiency of nutrient metabolism in farm animals suffers if the climatic conditions fall outside the thermoneutral environment. It should also be emphasized that poorer nutrient digestibility and efficiency of utilization both lead to a higher rate of nutrient excretion (i.e. $\mathrm{N}$ and $\mathrm{P}$ ), with a consequent negative impact on the environment. The higher rate of nutrient excretion damages the actual production potential as well as the product quality, and it also compromises the health status of feed producing animals with possible feed safety consequences.

\section{Feeding strategies in response to climate change}

Climatic conditions determine the energy and nutrient metabolism of farm animals. According to relevant data climate change leads to a higher mean ambient temperature, and it may even result in extreme weather in certain parts of the World. This calls for a discussion of feeding strategies in response to climate change, including nutritional manipulation and feeding during cold and heat stress.

\section{Feeding strategies during cold stress}

As earlier mentioned, animals consume more feed at low ambient temperatures in order to compensate for the increased energy requirement used in thermoregulation. From the aspect of energy requirements, a cold environment is essentially the equivalent of reduced energy supply, and thus higher feed intakes and higher energy intakes can meet the extra demand of thermogenesis. When the increased feed intake is prevented by the limitations of the animal's gastro-intestinal system, any means of boosting the dietary energy of the feed may be suitable for maintaining growth, and egg and milk production. Although increasing the dietary energy in a thermoneutral environment is associated with the improvement of feed conversion (the amount of feed required to produce $1 \mathrm{~kg}$ of product), in cold ambient temperatures, however, feed conversion may become worse or in the best case does not change with the feeding of high energy density diets due to the higher use of maintenance-i.e. non-productive-energy.

The body attempts to compensate for the excessive heat loss suffered in cold temperatures by a higher rate of heat production, and one component of this is to increase the use of maintenance energy. Heat, however, is also generated in the course of digesting and converting the dietary nutrients (the thermic effect of diet), which helps to maintain body temperature in conditions below the lower critical temperature; accordingly, the feeding of diets with a high thermic effect will help the animals cope with the too cold environment. Thus for example, when high fiber diets are fermented by the colon bacteria a relatively high portion of energy is lost as heat; and the oxidation of proteins / amino acids as a form of energy producing process also produces lot of heat. Therefore, feeds containing a high percentage of fermentable fibers or excess protein increase the heat production of the animals. In practical feeding, however, protein 


\section{Impact of climate change on livestock productivity: A review}

overfeeding is not recommended either from the economical or the environmental point of view.

\section{Feeding strategies during heat stress}

Since heat production after ingestion of the diet is high, farm animals reduce their feeding activity at high ambient temperatures, which bears significant consequences on their nutrient intake. The practice of feeding the daily ration in several smaller portions or during the cooler parts of the day follows from the above. Based on the previous sections other potential feeding strategies can be applied at the time of heat stress, which (i) reduce the heat production by the animals; (ii) compensate for the lower nutrient supply; and (iii) alleviate heat stress induced metabolic changes. It should be noted, however, that during severe heat stress these methods should be used in combination in order to maintain the production performance of the farm animals and the quality of their products.

\section{Methods to reduce the total heat production of livestock}

Methods to reduce total heat production of farm animals consist of (i) fat supplementation, (ii) feeding low protein diets with synthetic amino acids according to the ideal protein concept, and (iii) adding dietary betaine. In comparison to other nutrients, fat generates the least heat, either when deposited as body fat or when used for energy, thus high fat diets reduce the total heat production of the animals. Accordingly, fat supplementation moderates feed refusal, which is critical for the production potential. At the same time, fat supplementation boosts the energy density of the diet, as the energy content of fat sources (both of plant and of animal origin) is far the highest compared to the other nutrients and to compound feeds. By adding fat to the diet the energy requirement of the animals can be met accurately even if the feed intake decreases to some extent above the upper critical temperature. The so-called ideal protein refers to a welldefined amino acid pattern, which expresses the requirement of essential amino acids in percentage of lysine. The amino acid pattern of the ideal protein changes to some extent during the life of the animals in accordance with their level of production. Amino acid conversion and $\mathrm{N}$ excretion are the lowest when diets are formulated according to ideal protein concept. Excess amino acids that cannot be used in protein synthesis due to a limiting factor (such as a limiting amino acid, energy supply or genetic potential) are metabolized in the body. Compared to other nutrients, the oxidation of amino acids yields the most heat contributing to the total heat production. Consequently, the heat increment is higher when excess amino acids are present in the diet. The heat increment from protein metabolism is at the minimum if the dietary protein level meets the requirements of the animal, and if the amino acid content or even the ileal digestible amino acid content corresponds to the ideal protein concept. Betaine (trimethylglycine) is an intermediate metabolite in the catabolism of choline, which can modify the osmolarity, acts as a methyl donor, and has potential lipotropic effects. Schrama et al. (2003) showed that under thermoneutral conditions dietary betaine supplementation $(1.23 \mathrm{~g} / \mathrm{kg})$ reduced the total heat production of pigs. Moreover, recent studies repeatedly recommend using betaine in pig and poultry feeds during heat stress (Metzler-Zebeli et al., 2008), as being a methyl donor it can be used in the antioxidant defense (for glutathione-peroxidase) system, and it also efficiently inhibits the reduction in cell water retention. As previously mentioned, dietary fiber increases the heat production of the animals, and this raises the question as to how feed should be formulated for animals that require high levels of dietary 


\section{Madziga}

fiber, such as gestating sows and ruminants. In gestating sows, the diluted (low energy content) feed with high fiber content prevents the sows becoming overweight, which could otherwise lead to health problems and insufficient milk production during lactation. According to data reported by de Lange et al. (2006), the overall energy cost of ingesting and excreting indigestible material in growing pigs is very small, thus the use of poorly digestible fiber sources in gestating sow diets may be beneficial at high temperatures. In ruminants, high dietary fiber content supplied in the daily ration is indispensable for adequate rumen fermentation. Bearing in mind the positive correlation between the metabolizability of the diet and the efficiency of energy utilization, it can well be recommended to feed high quality forages and other highly digestible fiber sources to ruminants during heat stress. This will result in a somewhat lower heat production by the animals, in contrast to cows fed with poor quality forages. At the same time, it is probable that due to the extreme weather conditions high quality forages can only be produced using special agro techniques, which will increase their price. The role of drought resistant grasses (e.g. brome grass, tall fescue, crested wheatgrass, etc.) and leguminous species becomes more important in the flora of pastures for grazing animals (Babinszky et al., 2011); however, new varieties of grasses would likely be used requiring joint research projects of plant breeders with animal nutritionists. The above sections discussed the extent of feed refusal during heat stress and its effect on livestock performance. If the decrease in feed intake can be alleviated or prevented, the nutrient supply will meet the requirements of the animals for high production potential and good quality food production.

Compensating for reduced nutrient supply Since heat stress impairs feed intake and the digestibility of nutrients too, it is recommended to feed more concentrated diets with high levels of easily digestible nutrients in hot environments. This should be implemented with the use of various options offered by the feed manufacturing technologies (hydrothermic treatments, micronization), and also by increasing the level of dietary vitamins and minerals, and perhaps by improving their bioavailability. The bioavailability of nutrients can be achieved in part by enhancing the digestibility of nutrients in the small intestine (ileal digestibility) and also by boosting the utilization of absorbed nutrients (e.g. use of organic trace elements). Adding different enzyme supplementation to the diet can improve the ileal digestibility of nutrients, such as amino acids, carbohydrates and $\mathrm{Ca}$ and $\mathrm{P}$. It is suggested, however, to use substrate specific dietary enzymes (phytase, xylanase, $\beta$-glucanase, etc.) in accordance with the composition of feed. The use of methods that improve the digestibility and bioavailability of nutrients is also desirable from the aspect of environmental protection. Improving the digestibility and conversion of nutrients, and meeting the requirements of the animals accurately can serve to curb the environmental load from animal husbandry. At the same time, it should be stated that enhancing the nutritive value of animal diets becomes particularly important in hot climates.

\section{Alleviating heat stress induced metabolic changes}

The third group of nutritional strategies aims to alleviate the heat stress induced metabolic changes within the body. These are means to enhance the oxidative defense or alleviate the shift in electrolyte balance within the body. Several micronutrients possess direct or indirect anti-oxidative properties; those most extensively examined in farm animals are vitamin $\mathrm{C}, \mathrm{E}$ and $A$, zinc and selenium as well as methionine. According to the findings of 


\section{Impact of climate change on livestock productivity: A review}

relevant studies the nutrients listed in the above improve the defense of farm animals against lipid peroxidation; also the body requires more of these antioxidants during heat stress. This is why it should be stressed, that vitamin and mineral supplementation not always leads to the improvement of production performance or product quality of animals kept in hot environments, even though they are essential to maintaining their health status. The excretion of $\mathrm{Na}$ and $\mathrm{K}$ and the amount of water lost from the body increase during heat stress, which together may lead to a shift in the acid / base balance. Supplementing monovalent ions in the diet can lessen the decrease of water retention by the body. Salts suitable for the purpose are ammonium chloride, sodium and potassium bicarbonate, sodium and potassium hydro carbonate, potassium sulphate, etc., which can be equally used in poultry, swine and ruminant nutrition. With respect to alleviating the non-desirable consequences of climate change, the combined application of the options discussed in the above can counteract the negative impact of conditions outside the comfort zone of farm animals. Knowing the altered nutrient requirements and adjusting the nutrient supply to them can help to prevent the deterioration of production performance and product quality. However, in addition to precision feeding, housing should be adjusted to the climatic conditions as well, i.e. animals should be kept in well insulated, heated or cooled buildings, in accordance with the ambient temperatures. The most important action for alleviating the impact of heat stress is to open up enclosed buildings, in order to increase their cubic capacity. Outdoor pens become more important for breeding animals and further solutions can be to establish sprinkler systems, wallows, and to cool the buildings with adiabatic systems or heat exchangers (Babinszky et al., 2011). There is a consensus that genetic selection should aim to improve the heat tolerance of high producing farm animals without impairing their genetic potential. The continuously expanding poultry production in the tropical and subtropical regions of the Earth already necessitates the revision of selection strategies of breeding programs (Lin et al., 2006). There are promising results from efforts aimed at developing technologies to improve the adaptation of meat and egg type poultry to hot environments. The improvement of adaptive abilities to the changes of the ambient temperature besides maintaining the existing production potential will become one of the selection objectives and technical solutions in response to the climate change, and not only for poultry but for other farm animal species as well. Based on all this it can be concluded that the combined application of animal feeding and housing developments plus of genetic programs is required in order to maintain or even improve the production efficiency and product quality of farm animals despite the climate change.

\section{Conclusion}

The study showed that we should expect climate change to cause long-term changes in the environment, which in turn affect feed crop production and the production of farm animals. An important task facing feed crop breeders is to create feed crop varieties that as a result of the selective breeding efforts become more drought tolerant besides maintaining their average yields and nutrient contents. It will be our task as nutritionists to use these improved feed crop varieties in a highly focused and professional manner when formulating diets. When developing professional animal nutrition however, we should not only rely on traditional nutritional science but should also use the results of its related disciplines (microbiology, immunology, molecular biology, molecular genetics, digestive physiology, etc.) besides having a thorough 
knowledge of the energy metabolism of farm animals. As discussed earlier, there is a very close relationship between the energy metabolism of the animals and the ambient temperature, and the animal performance and the quality of their products. The knowledge of these factors enables us to alleviate by means of nutrition the stress caused by climate change and in consequence to produce high quality and safe foodstuffs meeting the requirement of human nutrition without increasing the environmental load of production. This also means that the different disciplines can only provide an adequate response to the challenges of climate change in cooperation. Therefore, climate researchers, meteorologists, plant breeders, crop producers, animal nutritionists, biologists, geneticists, livestock producers, animal housing technicians, nutrition biologists, doctors, etc. should all work together in the frames of a carefully structured and coordinated project to achieve this objective. The task is given, and its accomplishment depends on us only.

\section{References}

Aksit, M., Yalcın, S., Özkan, S., Metin, K. and Özdemir, D. 2006. Effects of Temperature During Rearing and Crating on Stress Parameters and Meat Quality of Broilers. Poultry S c i e n c e, 85 : 1867-1874.

Babinszky, L. 1998. Dietary Fat and Milk Production. In: The Lactating Sow, M.W.A. Verstegen, P.J. Moughan and J.W. Schrama (Eds), pp. 143157. Wageningen Perss, $\mathrm{W}$ a g e $\mathrm{n}$ i $\mathrm{ng}$ e $\mathrm{n}, \mathrm{T} \mathrm{h}$ e Netherlands.

Babinszky, L., Dunkel, Z., Tóthi, R., Kazinczi, G. and Nagy, J. 2011. The impacts of climate change on agricultural production, Hungarian Agricultural Research,
2:14-20.

Bandaranayaka, D. D. and Holmes, C. W. 1976. Changes in the composition of milk and rumen contents in cows exposed to a high ambient temperature with controlled feeding. Tropical Animal Health and Production, 8: 38-46.

Berman, A. 2005. Estimates of heat stress relief needs for Holstein dairy cows. Journal of Animal Science, 83, pp. 1377-1384.

Borges, S. A., Fischer da Silva, A. V., Ariki, J., Hooge, D. M. and Cummings, K. R. 2003. Dietary electrolyte balance for broiler chickens exposed to thermoneutral or heat-stress environments. Poultry Science, 82(3):428-435.

Collin, A., van Milgen, J., Dubois, S. and Noblet, J. 2001. Effect of high temperature on feeding behavior and heat production in grouphoused young pigs. Brit. Journal of Nutrition, 86: 63-70.

Close, W. H. 1989. The influence of thermal environment on the voluntary food intake of pigs. In: The voluntary food intake of pigs, J.M. Forbes, M.A. Varley, T.L.J. Lawrence, (Eds), pp. 87-96. British Society of Animal Production, Edinburgh.

Craine, J. M., EImore, A. J., Olson, K. C. and Tolleson, D. 2009. Climate change and cattle nutritional stress. Global Change Biology, 16 (10): 2901-2911.

Daghir, N. J. 2009 Nutritional Strategies to Reduce Heat Stress in Broilers and Broiler Breeders. Lohmann Information, 44(1): 6-15.

de Lange, C., van Milgen, J., Dubois, S. and Noblet, J. 2006. Energy cost of ingesting and excreting indigestible material in growing pigs is minimal. Animal Research 
Vol.55 pp.551-562.

FASS (Federation of Animal Science Societies). 2010. Guide for the Care and Use of Agricultural Animals in Research and Teaching, USA.www.fass.org/docs/agguide3 rd/Ag Guide 3rd ed.pdf

FAO. 2009. The state of food and agriculture, Rome, Italy http://www.fao.org/docrep/012/ i0680e/i0680e.pdf

Gaughan, J. B and Cawsell-Smith, A. J. 2015. Impact of climate change on livestock production and reproduction. In: Climate change Impact on livestock: adaptation and mitigation. Sejian, V., Gaughan, J., Baumgard, L., Prasad, C.S (Eds), Springer-Verlag $\mathrm{GMbH}$ Publisher, New Delhi, India, pp 51-60.

Gonzalez-Esquerra, R. and Leeson, S. 2005. Effects of Acute Versus Chronic Heat Stress on Broiler Response to Dietary Protein. Poultry Science, 84: 1562-1569.

Hai, L., Rong, D. and Zhang, Z. Y. 2000. The effect of thermal environment on the digestion of broilers. Journal of Animal Physiology and Animal Nutrition (Berl.) 83: 5764.

Halas, V., Dijkstra, J., Babinszky, L., Versegen, M. W. A. and Gerrits, W. J. J. 2004. Modeling of nutrient partitioning in growing pigs to predict their anatomical body composition: 1. Model description. British Journal of Nutrition, 92: 707-723.

Huynh, T. T. T., Aarnink, A. J. A., Verstegen, M. W. A., Gerrits, W. J. J., Heetkamp, M. J. W., Kemp, B. and Canh, T. T. 2005. Effects of increasing temperatures on physiological changes in pigs at different relative humidifies. Journal of Animal Science, 83: 1385-1396.

Kadzere, C. T., Murphy, M. R., Silanikove, N. and Maltz, E. 2002. Heat stress in lactating dairy cows: a review. Livestock Production Science, 77(1): 59-91.

Keane, M. G. and Allen, P. 1998. Effects of production system intensity on p e r form a n c e, c a r c a s s composition and meat quality of beef cattle. Livestock Production Science, 56:203-214

Kerr, B. J., Yen, J. T., Nienaber, J. A. and Easter, R. A. 2003. Influences of dietary protein level, a $\mathrm{m} \mathrm{i} \mathrm{n} \mathrm{o}$ acid supplementation and environmental temperature on performance, body composition, organ weights and total heat production of growing pigs. Journal of Animal Science, 81: 1998- 2007.

Lin, H., Jiao, H. C., Buyse, J. and Decuypere, E. 2006. Strategies for preventing heat stress in poultry. World's Poultry Science Journal, Vol.62: 71-86.

Lopez, J., Jesse, G. W., Becker, B. A. and Ellersieck, M. R. 1991. Effects of t e m perat u r o n the performance of finishing swine: I. Effects of a hot, diurnal temperature on average daily gain, feed intake, and feed efficiency. Journal of Animal Science, 69: 1843-1849.

McKee, S. R. and Sams, A. R. 1997. The effect of seasonal heat stress on rigor development and the incidence of pale, exudative turkey meat. Poultry Science, 76: 1616-1620.

Mashaly, M. M., Hendricks, G. L. and Kalama, M. A. 2004. Effect of Heat Stress on Production Parameters and Immune Responses 
of Commercial Laying Hens. Poultry Science, 83: 889-894.

Messias de Bragan ca, M., Mounier, A.M. \& Prunier, A. 1998. Does feed restriction mimic the effects of increased ambient temperature in lactating sow $\square$ Journal of Animal Science, 76: 2017-2024.

Metzler-Zebeli, B.U., Eklund, M., Rink, F., Bauer, E., Ratriyanto, A. and Mose nthin, R. 2008 . Nutritional and metabolic effects of betaine in pigs and poultry. In: Tagungsband Schweine- und Geflügelernährung. K. Eder (Ed), pp. 96-106, Universitätsdruckerei, Martin-Luther-Universität Halle-Wittenberg, Halle (Saale).

Noblet, J., Le Dividich, J. and van Milgen, J. 2001. Thermal environment and swine nutrition, In: Swine Nutrition, A.J. Lewis and L.L. Southern (Eds), pp. 519-544, CRC Press, Boca Raton, Florida, US.

NRC (National Research Council).1989. In: Nutrient Requirements of Dairy Cattle. $6^{\text {th }}$ Revised Edition Update. National Academy Press, Washington, DC. ISBN: 0-30903826-X

Quiniou, N., Dubois, S. and Noblet, J. 2000. Voluntary feed intake and feeding behaviour of grouphoused growing pigs are affected by ambient temperature and body weight Livestock Production Science, Vol. 63 (3): 245-253.

Ravagnolo, O. and Misztal I. 2000. Genetic Component of Heat Stress in Dairy Cattle, Parameter Estimation. Journal of Dairy Science, 83(9):2126-2130.

Renaudeau, D., Noblet, J. and Dourmad, J.Y. 2003. Effect of ambient temperature on mammary gland metabolism in lactating sows.
Journal of Animal Science, 81: 217-231.

Sahin, K., Kucuk, O., Sahin, N. and Sari, M. 2002. Effects of vitamin $C$ and $\mathrm{vitamin}$ E o n lipid peroxidation status, some serum hormone, metabolite, and mineral concentrations of Japanese quails reared under heat stress $\left(34^{\circ} \mathrm{C}\right)$. International Journal of Vitamin and Nutrition Research, 72: 91-100.

Sahin, N., Tuzcu, M., Ozercan, I., Sahin, K., Prasad, A.S. and Kucuk, O. 2009. Zinc picolinate in $\mathrm{th}$ e prevention of leiomyoma in Japanese quail. Journal of Medical Food,.12(6) :1368-74.

Schrama, J. W., Heetkamp, M. J. W., Simmins, P. H. and Gerrits, W. J. J. 2003. Dietary betaine supplementation affects energy metabolism of pigs. Journal of Animal Science, 81:1202-1209.

Scollan, N., Hocquette, J. F., Nuernberg, K., D a n n e n b e r g e r, D ., Richardson, I. and Moloney, A. 2006. Innovations in beef production systems that enhance the nutritional and health value of beef $1 \mathrm{ipids}$ and their relationship with meat quality. Meat Science, 74: 17-33.

Sejian, V. 2013. Climate change: Impact on production and reproduction, Adaptation mechanisms and mitigation strategies in small ruminants: A review. The Indian Journal of Small Ruminants, 19(1):1-21.

Sejian, V., Maurya, V. P., Kumar, K. and Naqvi, S. M. K. 2015. Effect of multiple stresses (thermal, nutritional and walking stress) on growth, physiological response, bloodbiochemical and endocrine responses in Malpura ewes under 


\section{Impact of climate change on livestock productivity: A review}

semi-arid tropical environment. TropicalAnimal Health and Production, 45:107-116.

Sejian, V., Gaughan, J. B., Raghavendra Bhatta and Naqvi, S. M. K. 2016. Impact of climate change on livestock productivity. Broadening Horizons N²6.
Silanikove, N., Maltz, E., Halevi, A. and Shinder, D. 1997. Water, Na, K and $\mathrm{Clmetabolism}$ in high yielding dairy cows at the onset of lactation. Journal of Dairy Science, 80: 949-956.

Received: $12^{\text {th }}$ October, 2020 Accepted: $5^{\text {th }}$ February, 2021 